\title{
Virtual and Augmented Reality in the Teaching and Learning of Programming: A Systematic Mapping Study
}

\author{
Gustavo Martins Nunes Avellar ${ }^{1}$, Ellen Francine Barbosa ${ }^{1}$ \\ ${ }^{1}$ Instituto de Ciências Matemáticas e de Computação (ICMC-USP) \\ Universidade de São Paulo - Departamento de Sistemas de Computação \\ Caixa Postal 668 - CEP 13560-970 - São Carlos (SP), Brasil \\ gustavo.avellar@usp.br, francine@icmc.usp.br
}

\begin{abstract}
As programming becomes a fundamental course in several areas of knowledge and a desirable competence in different sectors of society, many teaching and learning approaches have been developed to support students and instructors. This paper aims to understand and characterize the research area that merges Virtual (VR), Augmented (AR), and Mixed Reality (MR) with the teaching and learning of programming, since such technologies have become more and more popular and affordable nowadays. To achieve these goals, we conducted a systematic mapping study. The results reinforce the adoption of $V R$ and AR as tools to support the visualization and practice of programming concepts, as well as to increase students' motivation and engagement. Results also showed some opening issues and opportunities for research in short term, mainly in relation to the use of mobile devices and immersive VR.
\end{abstract}

Resumo. A programação tem se tornado uma disciplina fundamental em diversas áreas do conhecimento e uma competência desejada em diferentes setores da sociedade. Assim, diferentes abordagens de ensino e aprendizagem de programação têm sido desenvolvidas para estudantes e educadores. Este artigo busca compreender e caracterizar a área de pesquisa que agrega Realidade Virtual (RV), Aumentada (RA) e Misturada (RM) com o ensino e aprendizagem de programação, visto que tais tecnologias têm se tornado cada vez mais populares e acessíveis atualmente. Para isso, um mapeamento sistemático da literatura foi conduzido. Os resultados reforçam a adoção de $R V$ e $R A$ como ferramentas de apoio à visualização e prática de conceitos de programação, assim como para melhorar motivação e engajamento dos estudantes. Os resultados também mostraram algumas lacunas e oportunidades de pesquisa em curto prazo, principalmente em relação ao uso de dispositivos móveis e RV imersiva.

\section{Introduction}

Programming abilities have become a commonly required asset for most college and university students [Luxton-Reilly et al. 2018], as well as even among teenagers and children [Oh et al. 2013]. There is a need to prepare students and retrain the current professionals with the set of skills required by the new job positions and life in the new age, using the transformative potential of modern technologies in favor of the education [UNESCO 2018].

At the current stage of computer graphics and hardware for both computers and mobile devices, it is possible to create realistic virtual objects to supplement the real 
VIII Congresso Brasileiro de Informática na Educação (CBIE 2019)

Anais do XXX Simpósio Brasileiro de Informática na Educação (SBIE 2019)

world as well as insert users into a fully virtual environment, in which the physical presence or interaction would be impossible, expensive, or dangerous [Cardoso et al. 2017]. Therefore, Virtual (VR), Augmented (AR), and Mixed Reality (MR) enable the creation or replication of numerous situations of information visualization, manipulation, and problem solving, at several levels of detail and abstraction [Tori and Hounsell 2018]. All these features could help to minimize the problems and difficulties in the teaching and learning of programming, such as abstraction and motivation, as well as they reinforce the solutions proposed by several studies in the literature [Piteira and Costa 2013, Micael Souza et al. 2016]. Moreover, improving the teaching and learning resources available to instructors and students can only serve to empower them, since the teaching and learning process of programming is frequently based only on exercises lists and textual programming environments [Marcolino and Barbosa 2017].

The area of Education has much to gain using VR/AR/MR systems, since they are capable to create to the users a new way of visualizing concepts and experiencing situations [Tori and Hounsell 2018]. Due to these reasons, for instance, VR/AR/MR systems have been commonly adopted in the area of Health [Franklin et al. 2011]. Actually, the popularization and cheapening of the development and usage of VR/AR/MR systems have expanded the areas of knowledge that can benefit from them [Cardoso et al. 2017]. In this context, our objective is to identify the usage of VR/AR/MR in the CS education and, more specifically, in the teaching and learning of programming concepts.

In this sense, we conducted a systematic mapping study in order to present an overview of the state of the art of VR, AR, and/or MR systems as tools to support the teaching and learning of programming. We focused on understand and characterize the entire setup used by the systems, including hardware platform, VR/AR/MR technical specifications, and how the system is visually presented to the user. Furthermore, we also intend to identify the system's target audience, topics of programming covered, and software development tools.

This paper is organized as follows. Section 2 describes the protocol we followed to conduct our mapping study. Section 3 shows the selected studies and the answers to our research questions. Section 4 summarizes the main results, also highlighting some threats to validity. Section 5 presents our conclusions and perspectives for future work.

\section{Research Method}

In order to define the research protocol and to conduct the systematic mapping study, we followed the guidelines of [Petersen et al. 2015]. The research method includes the following phases: (i) definition of the systematic mapping scope (section 2.1); (ii) retrieval methods and definition of evaluation criteria (sections 2.2 and 2.3); (iii) selection of relevant studies (section 2.4); and data extraction from selected studies (section 2.5).

\subsection{Research Questions}

With the purpose of identifying relevant information and assisting the definition of research questions (RQ), we adopted the method created by [Petticrew and Roberts 2006], entitled PICOC (Population, Intervention, Comparison, Outcome, Context). Thus, considering the context of teaching and learning of programming, we created the following research questions: 
VIII Congresso Brasileiro de Informática na Educação (CBIE 2019)

Anais do XXX Simpósio Brasileiro de Informática na Educação (SBIE 2019)

RQ 1: What is the Virtual, Augmented, and/or Mixed Reality system setup?

RQ 1.1: What is the hardware platform?

RQ 1.2: What are the technical specifications related to VR/AR/MR?

RQ 1.3: How is the VR/AR/MR content visually presented to the user?

RQ 2: What is the target audience?

RQ 3: What topics of programming are covered?

RQ 4: What software development tools are used?

\subsection{Search Strategy}

We performed the search for studies as a two-step process: (i) an automatic search in databases; and (ii) a manual search specifically for Brazilian's studies.

The automatic search was performed in four different digital libraries and electronic search engines: ACM Digital Library ${ }^{1}$, Engineering Village ${ }^{2}$, IEEE Digital Library $^{3}$, and Scopus ${ }^{4}$. We selected these databases since they are among the more frequently used in systematic reviews [Zhang et al. 2011].

In order to perform the automatic search, we defined the following search string and used it against studies metadata: (teaching OR learning) AND (programming) AND (virtual reality $\mathbf{O R}$ augmented reality $\mathbf{O R}$ mixed reality).

We used keywords related to our scope, such as Virtual Reality, Augmented Reality and Mixed Reality, as well as teaching and learning of programming. The inclusion of the term Mixed Reality is fundamental to ensure the retrieval of studies that are not clearly classified as VR or AR systems, but refer somehow to the Virtual Reality Continuum [Milgram et al. 1994].

After, we performed a manual search for relevant studies in Brazilian's conferences and journals databases (SBIE, RBIE, SVR, SBGames), which we consider more likely to have publications related to our interest area. The time window considered for publications was chosen accordingly to time window of the the selected studies retrieved by the automatic search (2008-2018). We also performed a search for Brazilian's studies with the same parameters on Google Scholar.

\subsection{Selection Criteria}

The selection criteria allow the inclusion of studies that would potentially answer our research questions, as well as the exclusion of non-relevant, incomplete, unavailable, or duplicated studies. We chose to have studies in English, since it is the mostly used language in publications, and in Portuguese, in order to investigate the research area in the Brazilian context as well. Also, there was no search limitations related to publication year or target audience. Thus, we only selected studies that support the teaching and learning of programming using systems based on VR, AR, and/or MR.

\footnotetext{
${ }^{1}$ https://dl.acm.org

${ }^{2}$ https://www.engineeringvillage.com

${ }^{3}$ https://ieeexplore.ieee.org

${ }^{4}$ https://www.scopus.com
} 
VIII Congresso Brasileiro de Informática na Educação (CBIE 2019)

Anais do XXX Simpósio Brasileiro de Informática na Educação (SBIE 2019)

\subsection{Studies Selection}

We obtained 2249 studies from the automatic search. After removing duplicated studies, 1263 studies remained. Figure 1 provides an overview of the mapping study phases. During a preliminary selection we read title, keywords, and abstract of the studies. Therefore, 46 potentially relevant studies were selected.

In order to reduce the chances of erroneous selection, we performed a final selection in which we entirely read each one of the 46 studies selected. As a result, 15 studies from automatic search were kept, and only one study was selected through the manual search that we performed for Brazilian's studies, resulting in a sample of 16 selected studies. The mapping study was conducted from June to November 2018. The complete protocol along with the selected studies references and the detailed description on them can be found at https://bit.ly/3272bHl

\subsection{Data Extraction}

We extracted the following items from each paper: title; authors; bibliographic reference; hardware platform used; description of the VR/AR/MR system; VR/AR/MR specifications; target audience; content of programming; and software development tools.

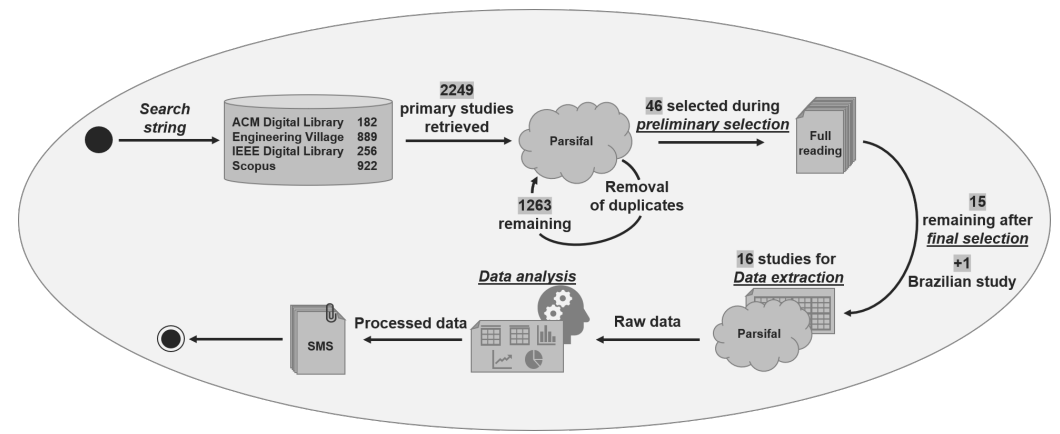

Figure 1. Systematic mapping study overview

\section{Results}

In this section, we present an analysis of the extracted data with the purpose of answer our research questions. Table 1 summarizes the selected studies. Figure 2 reveals the temporal distribution of the studies along with their countries.

\subsection{RQ 1: System Setup}

We considered setup as the system's main attributes, such as: (i) system's hardware platform; (ii) VR, AR, and/or MR technical specifications; and (iii) how the VR, AR, and/or MR content is visually presented to the user.

RQ 1.1: Hardware Platform: Besides the even distribution between studies that implement VR or AR, computers are the most common hardware platform for both VR (S2, S3, S4, S5, S8, S9, S11, S12) and AR (S1, S6, S7, S10, S14) systems. Also, we could not find studies that implement any other level of MR, considering the Reality-Virtuality Continuum [Milgram et al. 1994]. 
VIII Congresso Brasileiro de Informática na Educação (CBIE 2019)

Anais do XXX Simpósio Brasileiro de Informática na Educação (SBIE 2019)

\begin{tabular}{|l|l|l|}
\hline ID & Reference & \multicolumn{1}{c|}{ Title } \\
\hline S1 & [Ortega et al. 2017] & $\begin{array}{l}\text { iProg: Development of Immersive Systems for the Learning of } \\
\text { Programming }\end{array}$ \\
\hline S2 & [Vosinakis et al. 2014] & A platform for teaching logic programming using virtual worlds \\
\hline S3 & [Chandramouli et al. 2014] & $\begin{array}{l}\text { A fun-learning approach to programming: An adaptive Virtual } \\
\text { Reality platform to teach programming to engineering students }\end{array}$ \\
\hline S4 & [Oh et al. 2013] & $\begin{array}{l}\text { The Digital Dream Lab: Tabletop puzzle blocks for exploring } \\
\text { programmatic concepts }\end{array}$ \\
\hline S5 & [Vincur et al. 2017] & Cubely: Virtual reality block-based programming environment \\
\hline S6 & [Teng and Chen 2012] & $\begin{array}{l}\text { An augmented reality environment for learning openGL } \\
\text { programming }\end{array}$ \\
\hline S7 & [Mota et al. 2018] & Augmented reality mobile app development for all \\
\hline S8 & [Stigall and Sharma 2017] & $\begin{array}{l}\text { Virtual reality instructional modules for introductory } \\
\text { programming courses }\end{array}$ \\
\hline S9 & [Sharma and Ossuetta 2017] & $\begin{array}{l}\text { Virtual reality instructional modules in education based on } \\
\text { gaming metaphor }\end{array}$ \\
\hline S10 & [Masso and Grace 2011] & Shapemaker: A game-based introduction to programming \\
\hline S11 & [Díaz et al. 2008] & $\begin{array}{l}\text { Role-play virtual environments: Recreational learning of } \\
\text { software design }\end{array}$ \\
\hline S12 & [Chandramouli and Heffron 2015] & A Desktop VR-based HCI framework for programming instruction \\
\hline S13 & [Figueiredo et al. 2016] & Learning programming and electronics with augmented reality \\
\hline S14 & [Mesía et al. 2016] & $\begin{array}{l}\text { Augmented reality for programming teaching: Student } \\
\text { satisfaction analysis }\end{array}$ \\
\hline S15 & [Magnenat et al. 2015] & $\begin{array}{l}\text { Enhancing Robot Programming with Visual Feedback and } \\
\text { Augmented Reality }\end{array}$ \\
\hline S16 & [Carvalho et al. 2016] & $\begin{array}{l}\text { Ensino da estrutura de repetição For em Python com realidade } \\
\text { aumentada através do Aurasma }\end{array}$ \\
\hline
\end{tabular}

Table 1. Primary studies selected

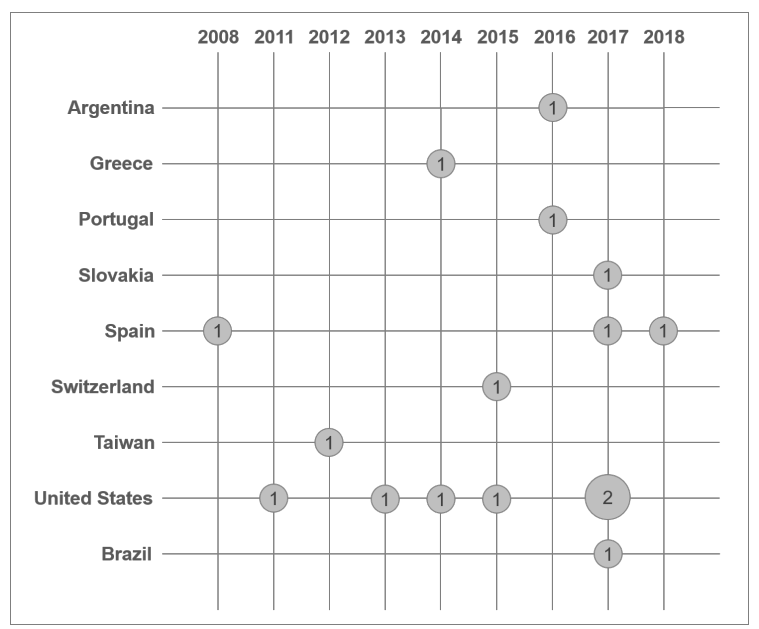

Figure 2. Selected studies distribution per year and country

AR systems contemplate two common hardware platforms available nowadays, i.e., computers and mobile devices (Figure 3). Even though the increasing popularization, low cost and flexibility of development for mobile applications with VR and/or AR [Popolin Neto et al. 2015, Tori and Hounsell 2018], we could not find any mobile VR system. On the other hand, we obtained three mobile AR systems (S13, S15, S16).

RQ 1.2: VR/AR/MR Technical Specifications: According to the VR definitions, it is possible to characterize these systems regarding to the perception of immersion and presence 
VIII Congresso Brasileiro de Informática na Educação (CBIE 2019)

Anais do XXX Simpósio Brasileiro de Informática na Educação (SBIE 2019)

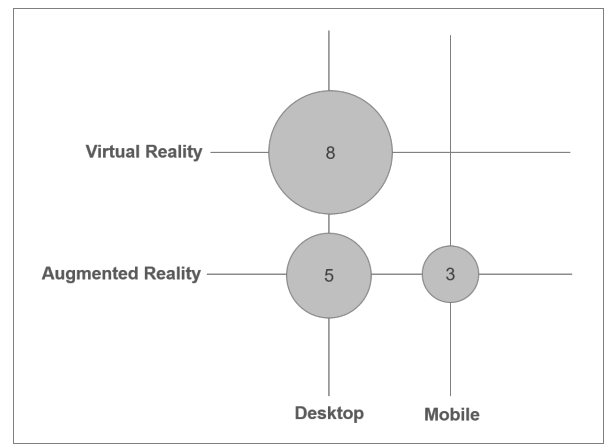

Figure 3. VR and AR systems distribution per platforms

provided. AR systems can be classified according to the tracking mechanism used and how the user visualizes the system [Tori and Hounsell 2018]. In this regard, five specifications categories were created, as shown in Figure 4.

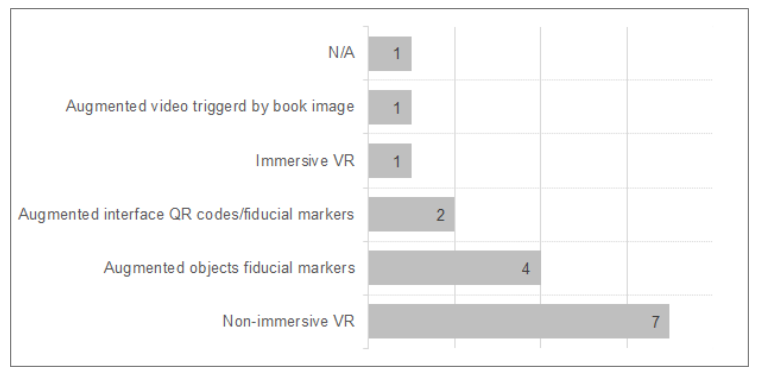

Figure 4. VR and AR systems distribution per technical specifications

The most common specification presented in the VR systems selected is nonimmersive VR systems for computers (S2, S3, S4, S8, S9, S11, S12). The second most common category is AR based on vision and fiducial markers (S6, S7, S14, S15, S16). It is also important to mention that one study approached the use of immersive VR (S5), two studies employed an augmented interface through QR codes (S10) and fiducial markers (S16), and one study used augmented video triggered using images from a book (S13). Lastly, although mentioning the use of AR, a single primary study does not provide any information concerning AR technical specifications (S1).

RQ 1.3: VR/AR/MR Content Presentation: AR systems were supported by teaching and learning methods based on the visualization and manipulation of augmented objects, which can represent abstract programming concepts (S1, S6, S7, S10, S14, S16), provide real-time feedback (S15), and show augmented videos (S13). On the other hand, VR systems were presented as virtual environments for straightforward manipulation, such as value entries, changes in objects and texts format, positioning, size, and color (S3, S4, $\mathrm{S} 12$ ); and as virtual worlds, allowing more interactive experiences, fostering exploration and guiding users using different narratives (S2, S5, S8, S9, S11).

\subsection{RQ 2: Target Audience}

Figure 5 reveals that researchers have focused on a wide range of target audiences while developing their systems. When we classify the audience with respect to the students' level of education, this includes preschool children (S4, S15), elementary school students 
VIII Congresso Brasileiro de Informática na Educação (CBIE 2019)

Anais do XXX Simpósio Brasileiro de Informática na Educação (SBIE 2019)

(S5, S15), middle school students (S5, S13, S15), high school students (S5, S15), undergraduate and graduate adults (S2, S3, S6, S8, S9, S12, S14, S16), and professors (S7). Lastly, it was necessary to create a category called General Students (S1, S10, S11) due to the lack of clear information. This category indicates that the system is not intended for a restricted target audience, but it can be widely used by students of different ages and backgrounds.

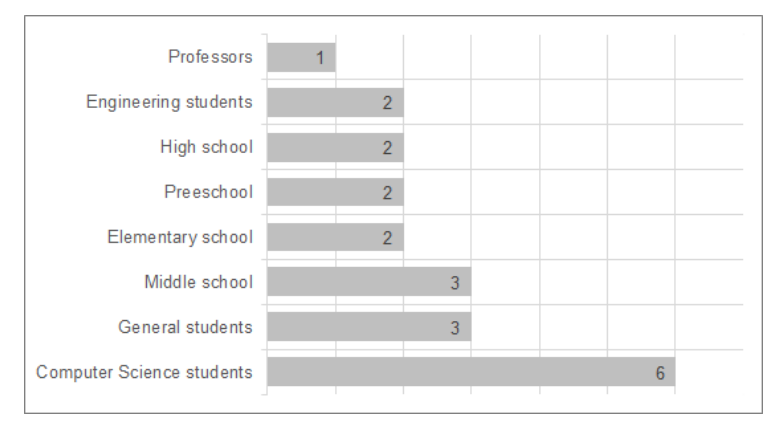

Figure 5. Target audiences distribution

\subsection{RQ 3: Topics of Programming}

Although there are variety of covered programming topics among the studies, most of them demonstrated a common interest towards the fundamental concepts of programming. The majority of studies are focused on the teaching and learning of more than one topic of programming (Figure 6). The studies approached programming concepts which are independent of programming languages, such as object-oriented programming (OOP) (S3, S8, S11, S12), logic structures (S5, S12, S14), data types (S3, S5, S12), loops (S5, $\mathrm{S} 12, \mathrm{~S} 14)$, arrays (S9, S12), basic programming logic (S1, S4), and so forth. Notwithstanding, some primary studies are focused on specific programming languages and interfaces, as Prolog (S2), Arduino Scratch (S13), OpenGL (S6), and Python, specifically the for command with the range function (S16).

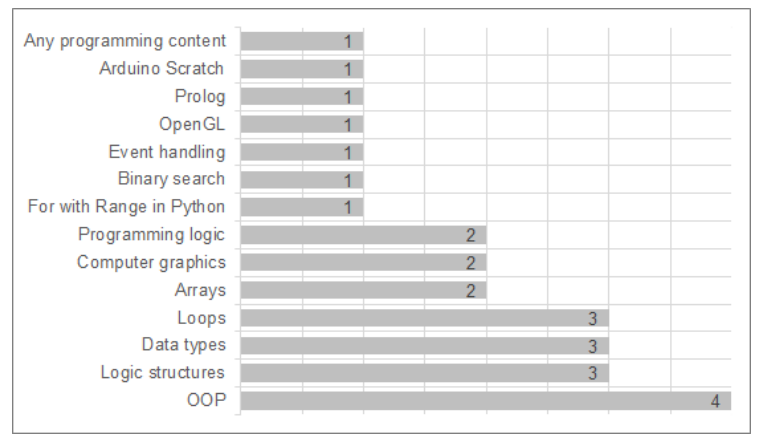

Figure 6. Selected studies programming content distribution

\subsection{RQ 4: Software Development Tools}

Despite some studies do not provide any information about this topic (S1, S3, S11, S12, S13), it was possible to find several development tools (Figure 7). Briefly, the selected studies adopted simulators, game engines, programming languages, development kits, 
VIII Congresso Brasileiro de Informática na Educação (CBIE 2019)

Anais do XXX Simpósio Brasileiro de Informática na Educação (SBIE 2019)

and programming libraries. We got the following arrangements of tools: (i) OpenSimulator (S2); (ii) Unity 3D (S5); (iii) Unity 3D and ReacTIVision (S4); (iv) OpenGL and ARToolKit (S6); (v) App Inventor, Java Android, Vuforia, OpenGL, and jPCT-AE 3D Engine (S7); (vi) Vizard and Python (S8, S9); (vii) Java and other libraries (S10); (viii) Flash Builder, FLARManager, and LibsPark (S14); (ix) Unity 3D and Vuforia (S15); and (x) Aurasma (S16).

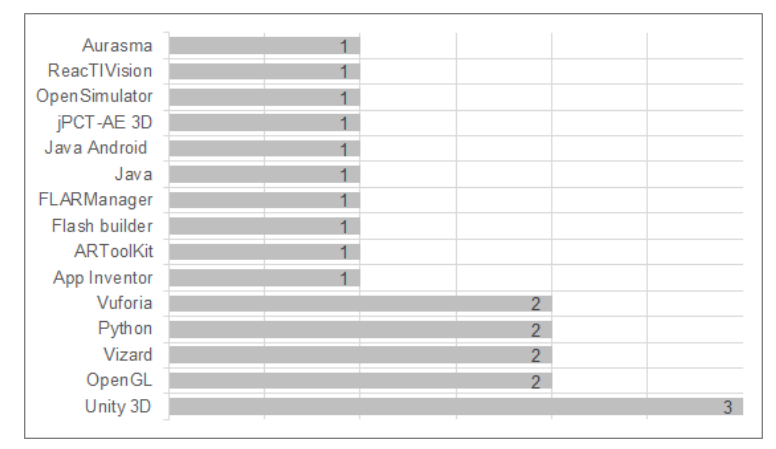

Figure 7. Selected studies software development tools distribution

\section{Discussion}

Virtual and Augmented Reality systems have been successfully used as effective supporting mechanisms for the visualization and practice of programming concepts. The success is in part due to the visual appealing and enjoyable context that promote experimentation and creativity [Mota et al. 2018]. Besides, VR, AR, and MR are capable to create to the users a new way of visualizing abstract concepts and experiencing situations, increasing levels of motivation and engagement [Tori and Hounsell 2018].

Considering the systematic mapping conducted, we noticed the group of selected studies was evenly distributed between VR and AR. For instance, we observed that adding virtual objects to the real world and let the user interact with them is an interesting approach to help visual abstraction and understanding of programming concepts, such as data types, loops and logic structures (S14). On the other hand, augmented visual interfaces were highlighted as supporting mechanisms to help teaching and learning programming, as in reading $\mathrm{QR}$ codes and fiducial markers to translate verbal criteria into programming code (S6, S10, S16).

We also found virtual environments as straightforward virtual interfaces for exploring and practicing programming concepts through conventional desktop peripheral devices (S3 and S12) or unconventional interaction methods, such as tangible puzzle pieces (S4). However, only one primary study implemented immersive VR (S5). The viewer (or Head-Mounted Display) used was the HTC Vive and the immersive VR world was designed to support students in programming through exercise solving using BlockBased Programming in a Minecraft video game themed world (S5).

Further, we identified a research gap regarding mobile learning applications and immersive VR systems. This contrasts with the evolution and significant support for the development of mobile applications, which is quite popular and affordable nowadays [Popolin Neto et al. 2015, Tori and Hounsell 2018]. Even though there are studies related to the adoption of VR/AR/MR in Education [Franklin et al. 2011], and also in Computer 
VIII Congresso Brasileiro de Informática na Educação (CBIE 2019)

Anais do XXX Simpósio Brasileiro de Informática na Educação (SBIE 2019)

Science education [Herpich et al. 2014], they still represent only a small portion of the research works conducted nowadays. In addition, among the selected studies, we noticed that formal evaluations of the systems are seldom conducted.

Finally, it is important to point out that our systematic mapping study contains some threats to validity. First, we may have missed important studies during the automatic search. To mitigate this threat, we created a generic search string, which was calibrated by switching its keywords several times and comparing the amount of results among the databases. At this point, we noticed that the terms teaching and learning were broadly used in different research contexts and the term Virtual Reality has been commonly used outside its definitions. Second, during the study selection, it is possible that erroneously assessments occurred. In case of doubt or lack of clear information, our choice was to accept the study. Along with the full reading of the study, we take it to a second evaluation against the selection criteria. Third, some primary studies did not provide all information necessary to answer every research question in detail; so, eventually, data interpretation was necessary.

\section{Conclusions and Future Work}

In this paper we provided an overview of the research on VR, AR and/or MR systems as tools to support the teaching and learning of programming concepts. To do so, we conducted a systematic mapping study to identify the systems that have been developed and used for this purpose. Our mapping resulted in 16 primary studies selected. Such studies were classified and categorized in order to answer our research questions, pointing out gaps and trends of investigation for further work in the area. We also identified reviews related to the AR and VR usage for educational purposes [Bacca et al. 2014, Muller Queiroz et al. 2017]. However, their goals differ from our mapping study that is focused specifically on the teaching and learning of programming.

There is several ways to address VR, AR, and MR to support the teaching and learning of programming. In the context of this mapping study, computers appeared as the most common platform for both VR and AR systems. Also, non-immersive VR standed out, with straightforward and sophisticated environments and worlds, as well as AR systems based on fiducial markers. In terms of target audience, the selected studies addressed a wide range of public, with emphasis on Computer Science students. Similarly, a diversity of programming topics have been considered, especially those related to fundamentals of programming. Lastly, regarding the development tools adopted, a game engine stands out.

As we could notice through the systematic mapping conducted, the adoption of VR and AR in the teaching and learning of programming is a research field in expansion, but it is still incipient, particularly in relation to the usage of mobile devices and immersive VR. As future work, we intend to propose and develop of a mobile immersive VR system to support the teaching and learning of programming concepts for children and teenagers.

\section{Acknowledgments}

This study was financed by the University of São Paulo (USP) and the Brazilian funding agencies: Coordenação de Aperfeiçoamento de Pessoal de Nível Superior - Brasil (CAPES) - Finance Code 001/Procad 071/2013, CNPq (134045/2018-1), and FAPESP. 
VIII Congresso Brasileiro de Informática na Educação (CBIE 2019)

Anais do XXX Simpósio Brasileiro de Informática na Educação (SBIE 2019)

\section{References}

Bacca, J., Baldiris, S., Fabregat, R., Graf, S., and Kinshuk, D. (2014). Augmented reality trends in education: A systematic review of research and applications. Educational Technology and Society, 17:133149.

Cardoso, A., Mackenzie, I. F., Kirner, C., and Tori, R. (2017). Development of educational resources with virtual and augmented reality: Challenges and perspectives. In XLIII Latin American Computer Conference (CLEI).

Franklin, F. F., Borges, A. C., and dos Santos, E. C. B. (2011). Um sistema interativo com realidade aumentada como ferramenta de ensino-aprendizagem em diabetes mellitus. In XXII Simpósio Brasileiro de Informática na Educação (SBIE).

Herpich, F., Jardim, R. R., Nunes, F. B., Voss, G. B., Fontoura, L. M., and Medina, R. D. (2014). Virtual lab: An immersive tool to assist in the teaching of software engineering. In XVI Symposium on Virtual and Augmented Reality (SVR).

Luxton-Reilly, A., Simon, Albluwi, I., Becker, B. A., Giannakos, M., Kumar, A. N., Ott, L., Paterson, J., Scott, M. J., Sheard, J., and Szabo, C. (2018). Introductory programming: A systematic literature review. In 23rd Conference on Innovation and Technology in Computer Science Education (ITiCSE).

Marcolino, A. S. and Barbosa, E. (2017). A survey on problems related to the teaching of programming in brazilian educational institutions. In 2017 IEEE Frontiers in Education Conference (FIE).

Micael Souza, D., Helena da Silva Batista, M., and Barbosa, E. (2016). Problemas e dificuldades no ensino de programação: Um mapeamento sistemático. Revista Brasileira de Informática na Educação, 24.

Milgram, P., Takemura, H., Utsumi, A., and Kishino, F. (1994). Augmented reality: a class of displays on the reality-virtuality continuum. 2351 .

Mota, J. M., Ruiz-Rube, I., Dodero, J. M., and Arnedillo-Sánchez, I. (2018). Augmented reality mobile app development for all. Computers and Electrical Engineering.

Muller Queiroz, A. C., Tori, R., and Nascimento, A. (2017). Realidade virtual na educação: Panorama das pesquisas no brasil. In Brazilian Symposium on Computers in Education (Simpósio Brasileiro de Informática na Educação-SBIE), page 203.

Oh, H., Deshmane, A., Li, F., Han, J. Y., Stewart, M., Tsai, M., Xu, X., and Oakley, I. (2013). The Digital Dream Lab: Tabletop puzzle blocks for exploring programmatic concepts. International Conference on Tangible, Embedded and Embodied Interaction.

Petersen, K., Vakkalanka, S., and Kuzniarz, L. (2015). Guidelines for conducting systematic mapping studies in software engineering: An update. Information and Software Technology, 64.

Petticrew, M. and Roberts, H. (2006). Systematic Reviews in the Social Sciences: A Practical Guide. Blackwell Pub.

Piteira, M. and Costa, C. (2013). Learning computer programming: Study of difficulties in learning programming. pages $75-80$.

Popolin Neto, M., Agostinho, I. A., Dias, D. R. C., Rodello, I. A., and Brega, J. R. F. (2015). A realidade virtual e o motor de jogo unity.

Tori, R. and Hounsell, M. d. S. (2018). Introdução a realidade virtual e aumentada. Editora SBC, Porto Alegre (RS).

UNESCO (2018). Skills for a connected world: Report of the unesco m-learning week.

Zhang, H., Babar, M. A., and Tell, P. (2011). Identifying relevant studies in software engineering. Information and Software Technology, 53. 